$$
N 73-11974
$$



\title{
POLLUTION MEASUREMENTS OF A SWIRL-CAN COMBUSTOR
}

by Richard W. Niedzwiecki and Robert E. Jones Lewis Research Center Cleveland, Ohio

TECHNICAL PAPER proposed for presentation at Eighth Propulsion Joint Specialists Conference sponsored by the American Institute of Aeronautics and Astronautics and the Society of Automotive Engineers New Orleans, Louisiana, November 29-December 1, 1972 


\title{
POLLUTION MEASUREMENTS OF A SWIRL-CAN COMBUSTOR
}

\author{
by Richard W. Niedzwiecki and Robert E. Jones \\ Lewis Research Center \\ National Aeronautics and Space Administration \\ Cleveland, Ohio
}

\begin{abstract}
Pollutant levels of oxides of nitrogen, unburned hydrocarbons and carbon monoxide were measured for an experimental, annular, swirl-can combustor. The combustor was 42 inches in diameter, incorporated 120 modules and was specifically designed for elevated exit temperature performance. Test conditions included combustor inlet temperatures of $600^{\circ}, 900^{\circ}$ and $1050^{\circ} \mathrm{F}$, inlet pressures of 5 to 6 atmospheres, reference velocities of 69 to 120 feet per second and fuel-air ratios of 0.014 to 0.0695 . Tests were also conducted at a simulated engine idle condition. Results demonstrated that swirl-can combustors produce oxides of nitrogen levels substantially lower than conventional combustor designs. These reductions are attributed to reduced dwell times resulting from short combustor length, quick mixing of combustion gases with diluent air, and to uniform fuel distributions resulting from the swirl-can approach. Radial staging of fuel at idle conditions resulted in substantial increases in combustion efficiencies and corresponding reductions in pollutant levels.
\end{abstract}

\section{INTRODUCTION}

This report presents measured combustor exhaust pollutant levels of oxides of nitrogen, unburned hydrocarbons and carbon monoxide, describes factors controlling their formation, and demonstrates reductions in oxides of nitrogen attainable with a swirl-can combustor.

Concern over air pollution has drawn the attention of combustion engineers to the quantities of exhaust emissions produced by gas turbine engines. Two general areas of concern have been expressed: urban pollution in the vicinity of airports and pollution of the stratosphere. The principal urban pollutants are unburned hydrocarbons and carbon monoxide during idle and taxi, and oxides of nitrogen and smoke during take-off and landing. Oxides of nitrogen are also considered to be the most predominant emission products formed during altitude cruise.

Altering gas turbine combustor designs to make substantial reductions in oxides of nitrogen will be an extremely difficult task, reference 1. Oxides of nitrogen are formed during any combustion process involving air. The amount formed is reaction rate controlled and is a function of flame temperature, dwell time of the combustion gases at high temperatures, concentrations of nitrogen and oxygen present and, to a somewhat lesser extent the combustor pressure. Flame temperatures increase as the combustor inlet temperature increases and as the primary zone fuel-air ratio approaches stoichiometric values. Dwell time is affected-by combustor primary zone length and reference velocity. Trends in combustor operating conditions indicate a steady increase in inlet temperature due to increasing compressor pressure ratios, reference 2 . 
Page Intentionally Left Blank 
Past studies of swirl-can combustors, references 2 and 3 , have indicated that this combustor type offers several inherent advantages for redacing oxides of nitrogen. These advantages include:

1. Short combustor lengths with accompanying short recirculation zones are realized for burning and mixing. Thus dwell time is reduced.

2. Quick mixing of burning gases and diluent air occurs inasmuch as swirl-can combustors pass nearly all of the air flow through the primary combustion zone and large interfacial mixing areas exist between combustion gases and airflow around the swirl-cans 。

3. Premixing of fuel and air occurs upstream of the burning zone and produces a more uniform mixture of fuel and air thereby reducing localized intense burning. This effect is reinforced by the-large number of fuel entry positions.

The swirl-can combustor used in these tests was designed for operation up to stoichiometric fuel-air ratios. Most of the pollution data were obtained during the testing to stoichiometric conditions. Some data were also obtained parametically to illustrate the effects of reference velocity and inlet air temperature upon formation of oxides of nitrogen. : Data previously reported in reference 4 are also included at a simulated engine idle condition to illustrate how pollutant levels of unburned hydrocarbons and carbon monoxide can be successfully minimized by fuel staging. Pollutant concentrations of nitric oxide ( $\mathrm{NO}$ ), oxides of nitrogen ( $\mathrm{NO}+\mathrm{NO}_{2}$ ), unburned hydrocarbons and carbon monoxide are presented for the following spans of test conditions: Combustor inlet air temperature, $600^{\circ}, 900^{\circ}$ and $1050^{\circ} \mathrm{F}$; inlet pressure, 5 to 6 atmospheres; fuel-air ratio, 0.014 to 0.0695 ; and reference velocity, 69 to 120 feet per second.

APPARATUS AND PROCEDURE

Test Facility

Tests were conducted in a connected-duct component test facility at the Lewis Research Center. The details of the test facility and instrumentation are contained in appendixes $A$ and $B$ of reference 5 .

\section{Combustor Design}

The test combustor, shown in figures 1 and 2 is an annular design 20.25 inches long from the diffuser inlet to the combustor exit plane, and is 42 inches in diameter. The combustor is a swirl-can design and incorporates several unique features including a combustor module array. The array consists of 120 modules, positioned on three-circumferential rows; which distribute-combastion uniformly across the combustor annulus. All of the combustor airflow, exclusive of liner coolant flow passes through the array thus providing an abandance of air for all stages of the combustion process, as well as providing the capability for quick mixing of hot gases and diluent air. The only airflow introduced downstream of the 
array is liner cooling air which accounted for 4 to 7 percent of the total airflow. Performance of a prior model of this combustor over an extended exit temperature span has been described previously in reference 3.

\section{Combustor Modules}

A typical combustor module is shown schematically in figure 3. Each module consists of three components; a carburetor, swirler and flame stabilizer. In operation, the modules perform several functions: Each module premixes fuel with air, swirls the mixture, stabilizes combustion in its wake and provides large interfacial mixing areas between the bypass air through the array and combustion gases in the module wake. Several flame stabilizer designs have been employed: Three- of the designs are shown in figure 3.

\section{Test Conditions}

All tests were conducted with ASTM-Al liquid fuel. The fuel had an average hydrogen-carbon ratio of 0.161 and a lower heating value of 18600 Btu per pound.

Tests were conducted over a range of fuel-air ratios of 0.005 to 0.0695 . For combustor exit average temperatures below $2300^{\circ} \mathrm{F}$, a 5 -point radial traverse temperature and pressure rake was used to evaluate combustor performance, and all flow conditions of interest could be investigated. A choked nozzle was used to measure combustor performance for higher exit temperatures. Reference velocities were limited by the choked nozzle and with a $600^{\circ} \mathrm{F}$ inlet air temperature varied-from 100 feet per second at an exit temperature of $1700^{\circ} \mathrm{F}$ to 69 feet per second at an exit temperature of $3700^{\circ} \mathrm{F}$. Reference velocities for higher inlet air temperatures were proportionately affected: The test facility had a maximum pressure limitation of 6 atmospheres.

\section{Exhaust Gas Pollutant Sampling}

Concentrations of nitric oxide, total oxides of nitrogen, carbon monoxide, unburned hydrocarbons and-carbon dioxide were obtained with an on-line system. All samples were drawn from one circumferential location and at three radial locations at the combustor exit through the water cooled probe-shown in figure 4.

\section{Gas Sample System}

Approximately 30 feet of $3 / 8$ inch stainless steel line was used to transport the sample to the analytical instraments. In order to prevent condensation of water and to minimize adsorption-desorption effects of hydrocarbon compounds, the line was electrically heated to $310^{\circ} \cdot \mathrm{F}$. Sample line pressure was maintained at $10 \mathrm{psig}$ in order to supply sufficient pressure to the instruments.

The exhaust gas analysis system, shown in figure 5 , is a packaged unit consisting of four commercially available instruments along with associated peripheral equipment necessary for sample conditioning and instrument calibration." In addition to visual 
readout, electrical inputs were provided to the IBM 360 computer for on-line analysis and evaluation of the data.

The hydrocarbon content of the exhaust gas : was determined-by a Beckman Instruments Model 402 total Hydrocarbon Analyzer. This instrument is of the flame ionization detector type.

Concentrations of oxides of nitrogen were determined by a thermo Electron Corporation Model 10A Chemilaminescent analyzer. The instrument included a thermal convertor to reduce nitrogen dioxide:to nitric oxide: and was operated at $1290^{\circ} \mathrm{F}$.

Both carbon monoxide and carbon dioxide analyzers were of the nondispersive infra-red (NDIR) type (Beckman-Instruments model 315B). The CO analyzer had four ranges: 0-100 ppm, 0-1000 ppm, 0-1 percent, and 0-10 percent. This range of sensitivity was accomplished by using stacked cells of $0.25-$ and $13.5-$ inch length. The $\mathrm{CO}_{2}$ analyzer had two ranges, 0-5 percent and 0-15 percent, with a sample cell length of 0.125 inches.

\section{Analytical Procedure}

All analyzers were checked for zero and span prior to.tests. Since the analyzer console required only a few seconds for each instrument to switch from calibration to sample modes, it was possible to perform frequent checks to insure the calibration accuracy without disrupting testing.

Where appropriate, the measured quantities were corrected for water vapor removed. The correction included both inlet air humidity and water vapor from combustion. The equations used were obtained from reference 6 .

The emission levels of all of the constituents were converted to an emission index parameter. Emission index values were computed from the measured quantities as proposed by the SAE Committee E-3l (ref. 6). An alternate procedure based on metered fuel-air ratio was also employed. Using the latter technique, emission index values for any constituent, $X$, can be calculated by the following expression:

$$
E I_{x}=\frac{M_{x}}{M_{a}} \frac{1+f}{f}(x) \times 10^{-3}
$$

where:

$E I_{x}$ emission index in grams of $X / \mathrm{kg}$ of fuel burned

$\mathrm{M}_{\mathrm{X}}^{\mathrm{X}}$ molecular weight of $\mathrm{X}$

$M^{x}$ molecular weight of air

$f^{a}$ metered fuel-air ratio

(x) measured concentration of $X$ in $\mathrm{ppm}$

Both procedures yield identical results when the sample validity was good.

Since practical considerations limited exhaust gas sampling to only one circumferential location, attempts were made to verify that the gas sampling position was 
representative of pollutant levels at the combustor exit. Two fuel-air ratios were calculated. The first value was computed from measured quantities of carbon dioxide, carbon monoxide, and unburned hydrocarbons. The second fuel-air ratio was obtained from metered values of fuel and air. Fuel-air ratios obtained by both methods are shown in figure 6. All of the data presented: in this report, for which both values of fuel-air ratio were available, produced gas sample fuel-air ratios within plus or minus 15 percent of metered values.

\section{RESULTS AND DISCUSSION}

\section{Oxides of Nitrogen}

Nitrogen oxides are formed during any combustion process involving air. These oxides, commonly referred to as NO, consist primarily of Nitric Oxide (NO) and significantly lesser amounts of $\mathrm{Ni}$ trogen Dioxide ( $\left.\mathrm{NO}_{2}\right)$... $\mathrm{NO}$ concentrations and $\mathrm{NO}$ concentrations expressed in parts per million are shown in figure 7 . Test conditions were inlet temperatures of $600^{\circ}, 900^{\circ}$ and $1050^{\circ} \mathrm{F}$, a reference velocity span of 69 to 120 feet per second, inlet pressures of 4 to 6 atmospheres and a combustor exit temperature span of $1600^{\circ}$ to $3700^{\circ} \mathrm{F}$. In spite of the wide variances in test conditions nearly all of the data appear to fall along a straight line indicating that the formation rate of $\mathrm{NO}_{2}$ is constant. Exceptions occur where the fuel-air ratios are 0.064 or higher. $\mathrm{NO}_{2}^{2}$ concentrations are lower than expected in this range probably due to lack of available oxygen in the combustion zone.

By convention, succeeding figures present $\mathrm{NO}_{\mathrm{x}}$ concentrations in terms $\mathrm{NO}_{2}$ emission index values. NO emission index values can be obtained by using the curve of figure 7 and the ratio of molecular weights of $\mathrm{NO}_{2}$ and $\mathrm{NO}$.

Effects of inlet air temperature and fuel-air ratio on $\mathrm{HO}_{\mathrm{x}}$ formation are shown in figure 8. With $600^{\circ} \mathrm{F}$ inlet air, the emission index level increases from a value of about 3 at a fuel-air ratio of 0.018 to a peak value of 6.5 at a fuel-air ratio of 0.048 and then decreases and approaches a value of about 4.6 at a fuel-air ratio of 0.0695 . The shape of the emission index curve is affected by many factors such as reaction rates, availability of free oxygen and reaction zone temperatures. A simplified, qualitative model explaining formation rates in the three fuel-air ratio zones based on combustion data and visual observations of swirl-can combustors in operation is as follows: At lower fuel-air ratios, combustion proceeds rapidly and is completed a short distance from the module array since the major portion of

combustion air is supplied through the modules. Combustion is generally restricted to the module wakes. Bypass air through the array recirculates in the module wakes mixing with the combustion gases thas reducing flame temperatures and NO formation. As fuel-air ratio is increased; heat flux increases and flame is not restricted to the module wakes but propagates across the entire array. At this condition, highest reaction zone temperatures are probably attained and the rate-at which $\mathrm{NO}_{\mathbf{x}}$ is formed increases.

Further increases in fuel-air ratio cause additional effects to occur which cause the formation rate of $\mathrm{NO}$ to decrease. As fuel-air ratio-is increased, more of the oxygen is used in combustion and becomes unavailable for $\mathrm{NO}_{\mathrm{x}}$ formation. Also, the added fuel causes the fuel-air ratio in the vicinity of the modules to become overly rich thus reducing reaction zone temperatures and $\mathrm{NO}_{\mathrm{x}}$ formation. Accompanying the 
decrease in reaction zone intensity is an elongation of the reaction zone along the combustor axis. Thus hot gases have less combustor length to traverse and their residence time in the combustor decreases:- This condition appears to exist for fuel-air ratios between 0.048 to 0.0668 . Within this span combustor exit temperature continues to increase to a maximum value of $3720^{\circ} \mathrm{F}$ while emission index values decrease. Parts per million values level out and decrease also. Further increases in fuel-air ratio higher than 0.0668 indicate that additional oxygen is not available since exit temperatures decrease rather than increase.

The simplified model also suggests that performance parameters which increase reaction rates such as increased pressure and inlet temperature-would also increase NO formation. Sufficient spans of pressure: were not investigated due to facility limitations. However, increases in combustor inlet temperature to $900^{\circ}$ and $1050^{\circ} \mathrm{F}$, also shown in figure 8 , significantly increased $\mathrm{HO}_{\mathrm{x}}$ formation to 3 to 4 times values obtained with $600^{\circ} \mathrm{F}$ inlet air.

NO emission index values were reduced further by increasing combustor reference velocity. Figure 9 presents emission index data at $600^{\circ}$ F inlet air temperature, a span of exit temperatures and three reference velocities. The decreases in emission index level with increasing reference velocities are probably due to reduced dwell time of hot gases within the combustor.

Unburned Hydrocarbons and Carbon Monoxide

Emission index values of unburned hydrocarbons and carbon monoxide plotted against fuel-air ratio for three-combustor-inlet temperatures: are-presented in figures 10 and 11 , respectively. With $600^{\circ}$ F inlet air temperature, both pollutant values were high at the lowest fuel-air ratios and produced a combustion inefficiency of approximately 3 percent. Pollutant values then decreased with increasing fuelair ratio. However, both pollutant values again increased at the highest fuel-air ratios investigated probably because of a lack of available: oxygen in the combustion zone. At a fuel-air ratio of 0.0695 unburned hydrocarbons produced an inefficiency of approximately 1 percent. Carbon monoxide produced an inefficiency of approximately 7 percent. Both pollutant concentrations were substantialiy redaced at the higher inlet air temperatures.

The influence of reference velocity on unburned hydrocarbons and carbon monoxide are presented in figures 12 and 13 ; respectively. Unlike $N O$ concentrations which were lowest at the highest reference velocity; unburned hydrôcarbon and carbon monoxide concentrations increased with increasing reference velocity. - The reduced concentrations of $\mathrm{NO}_{\mathrm{x}}$ obtained by increasing reference velocity were compensated for by increases in the othe $\mathrm{x}$ pollutants... Thus, rather than increasing reference-velocity (for $\mathrm{NO}_{x}$ reduction), methods of reducing dwell-time of combustion gases such as reducing combustor length and facilitating quicker mixing would be preferable.

\section{Idle Tests}

Since the combustor was designed for high exit temperature operation, it is not surprising that a fallof of combustion efficiency; with corresponding increases in 
pollutant levels, occurs at low fuel-air ratios. The extent of this problem can be seen from the top curve of figure-14: As the combustor exit-temperature decreases, there is a notable rise in the unburned hydrocarbon-emission index.

Effects of fuel scheduling can be seen from the bottom curve of figure 14 . The number of fired modules was reduced from 120 to 104 by shutting off the fuel to onehalf of the inner module row: Emission index values were decreased from 30 to 60 percent for equivalent combustor-exit-temperatures with the greatest percentage decreases occurring at the highest combustor exit temperatures.

The combustor was tested at idle conditions with all of the modules supplied with fuel and also with each of the three module rows individualiy supplied with all the fuel. The test conditions were a combustor reference velocity of 26 meters per second ( $85 \mathrm{ft} / \mathrm{sec})$ and an inlet air temperature and pressure of $478 \mathrm{~K}\left(400^{\circ} \mathrm{F}\right)$ and 4 atmospheres, respectively.

Combustion efficiency:- Combustion efficiency results are presented in figure 15. Fuel-air ratios represent overall values and represent all the air and fuel supplied to the combustor. With al1 the modales supplied with fuel, combustion efficiencies were low and blowout occurred-at a fuel-air ratio of about $0.009 . \cdots$ Supplying all the fuel to the center module-row improved combustion efficiency somewhat but produced an efficiency of only 50 percent at a fuel-air ratio of 0.008 . "Supplying all the fuel to the outer module row increased combustion efficiency significantly. Supplying all the fuel to the inner modale row raised the combastion efficiency to nearly 100 percent.

Effects of fuel scheduling were greatest for the inner module row, since this row contained the lowest number of modules, and thus each module was supplied with proportionately more fuel for a given overall fuel-air ratio: The reason that scheduling fuel to the center module row produced only a small improvement in combustion efficiency was probably due to quenching resulting from the reduced blockage flame stabilizers that this row contained. The reduced blockage-caused-a proportionately larger amount of air to flow through the center of the array.

Unburned hydrocarbons and carbon monoxide. - Emission index values for unburned hydrocarbons and-carbon monoxide-are shown in figures 16 and-17, respectively. Both pollutants followed inversely the same trends as combustion efficiency. A further indication of quenching of the center modale row is shown in figure 17 , which shows carbon monoxide levels were higher for the center module row than when all the modules were supplied with fuel.

The lowest emission index values occurred with only the inner module row supplied with fuel. At a fuel-air ratio of $\theta .008$ the emission-index values were approximately 10 for hydrocarbons and 40 for carbon monoxide. Nitrogen-dioxide emission index concentrations were low and did not-exceed a value of 1 .

\section{SEMMARY OF RESULTS}

Pollutant concentrations of a full annulus swirl-can combustor were measured. These included concentrations of nitric oxide, total oxides of nitrogen, unburned 
hydrocarbons, and carbon monoxide: Test conditions were inlet air temperatures of $600^{\circ}, 900^{\circ}$ and $1050^{\circ} \mathrm{F}$, pressures of 5 to 6 atmospheres, fuel-air ratios of 0.014 to 0.0695 , and reference velocities " of 69 to 120 feet per second: "The following results were obtained:

1. With a $600^{\circ} \mathrm{F}$ inlet air temperature the maximum emission index value of oxides of nitrogen expressed as nitrogen dioxide was 6.5 and occurred at an intermediate fuel-air ratio of 0.048. Fmission index values were lower for both higher and lower fuel-air ratios.

2. Increasing the combustor inlet air temperature to $900^{\circ}$ and $1050^{\circ} \mathrm{F}$ increased nitrogen dioxide emission index values by factors of 3 to 4 at higher fuel air ratios.

3. A comparison of nitric oxide and oxides of nitrogen concentrations expressed in parts per mililion produced a straight line function indicating that the formation rate of nitrogen dioxide is constant in spite of wide variances in test conditions.

4. Increasing combustor reference velocity caused oxides of nitrogen concentrations to decrease by reducing dwell time of the hot combustor gases. - However, these reductions were compensated for by increased concentrations of unburned hydrocarbons and carbon monoxide caused by the higher reference velocities.

5. Unbumed hydrocarbons and carbon monoxide-concentrations were reduced by increasing combustor fuel-air ratio and combustor inlet air temperature.

6. At simulated engine idle conditions, significant improvements in combustion efficiency and accompanying reductions in pollatant- levels were realized by radial scheduling of fuel. Best results were obtained when al of the fuel was supplied to the inner module row. Combustion efficiencies near 100 percent were obtained. Unburned hydrocarbon and carbon monoxide-emission-index values were 10 and 40 grams per kilogram, respectively.

\section{REFERENCES}

1. Grobman, J, "Jet Engine Emission," Climatic Impact Assessment Program, Proceedings of the Survey Conference, DOT-TSC-0ST-72 -13, Sept. 1972, Department of Transportation, Washington, D.C.

2. Anon., "Aircraft propulsion," SP-259, 1971, NASA, Washington, D.C.

3. Niedzwiecki, R. W., Juhasz, A. J., and Anderson, D. N., "Performance of a Swirl-Can Primary Combustor to Outlet Temperatures of $3600^{\circ} \mathrm{F}$ (2256 K)," TM X-52902, 1970, NASA, Cleveland, Ohio.

4. Niedzwiecki, R. W., Trout, A. M., and Mularz, E., "Performance of a Swirl-Can Combustor at Idle Conditions," TM X-2578, 1972, NASA, Cleveland, Ohio.

5. Wear, J. D., Perkins, P. J., and Schultz, D. F., "Tests of a Full-Scale Annular Ram-Induction Combustor for a Mach 3 Cruise Turbojet Engine," TN D-6041, 1970, NASA, Cleveland, Ohio.

6. Anon., Procedure for the Continuous Sampling and Measurement of Gaseous Emissions From Aircraft Turbine Engines," ARP 1256, Oct. 1971, SAE, New York, N.Y. 


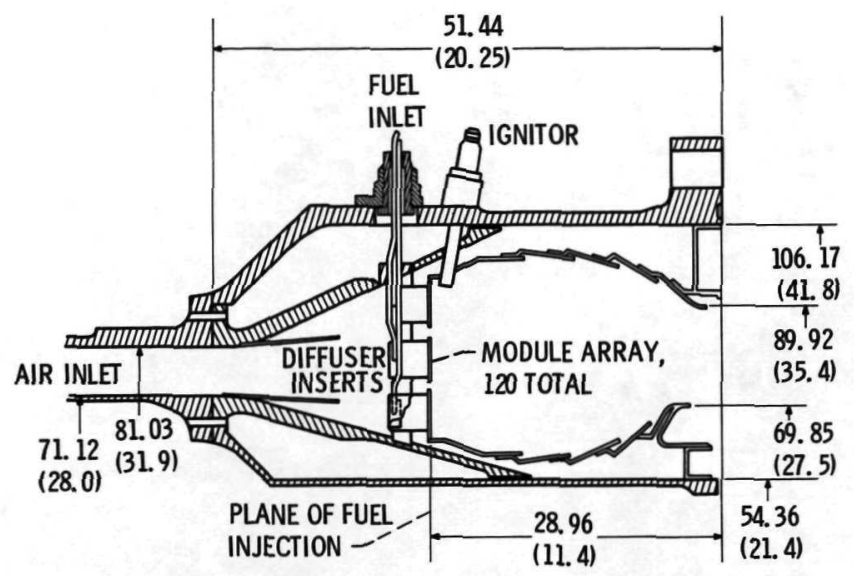

Figure 1. - Full annular model of high-temperature combustor. (Dimensions in centimeters (in.).)

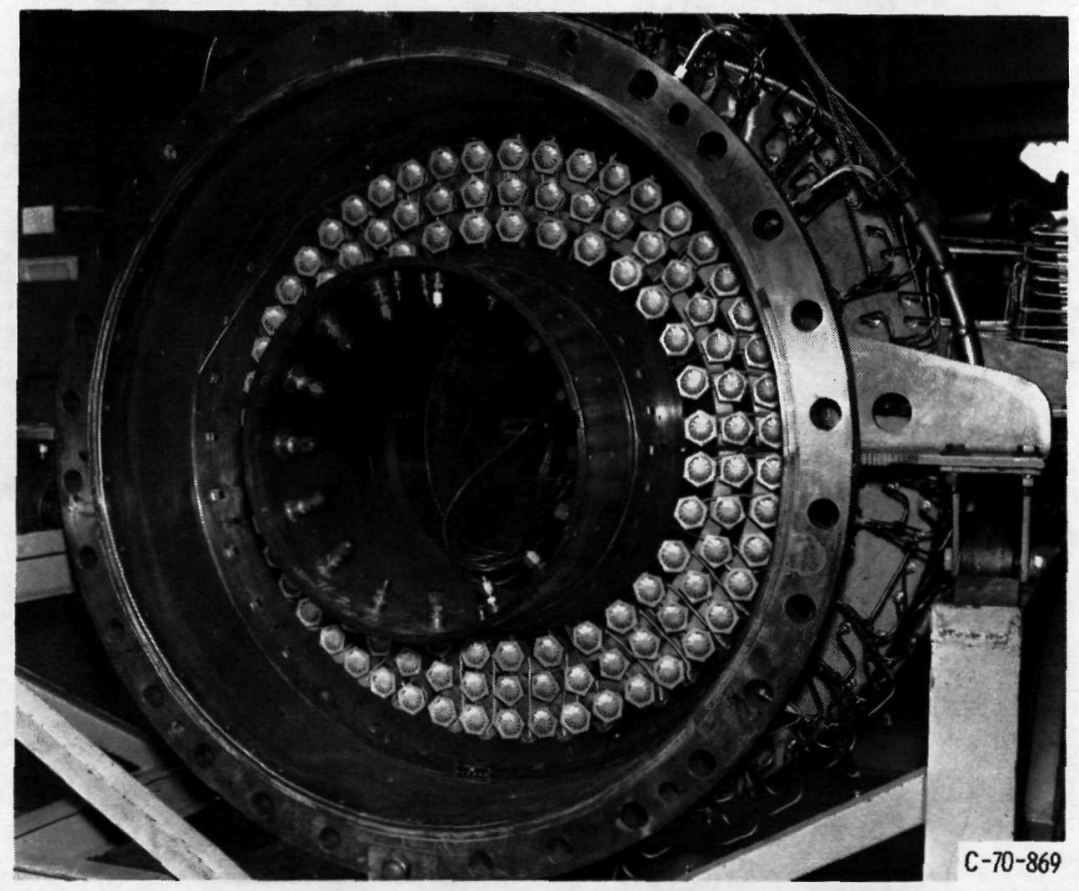

Figure 2. - Annular swirl-can-modular combustor. 

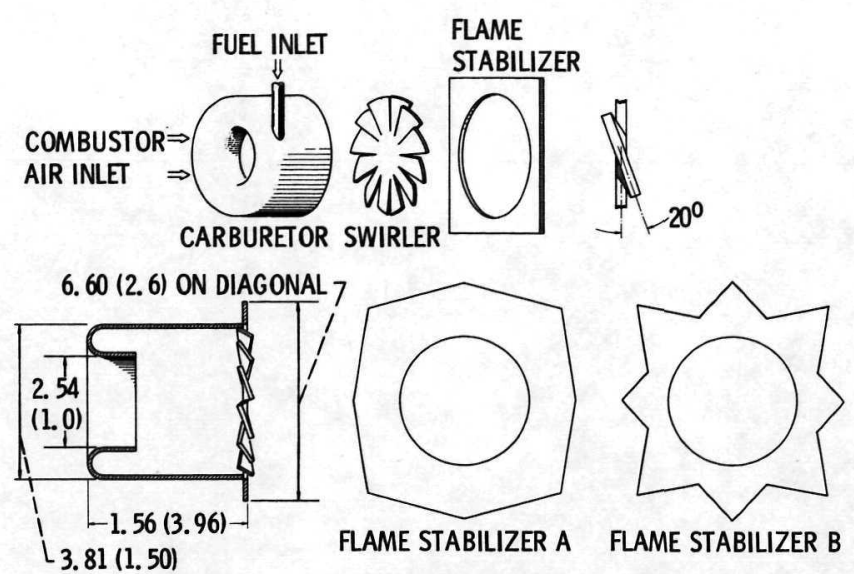

Figure 3. - Combustor module details. (Dimensions in centimeters (in.).)

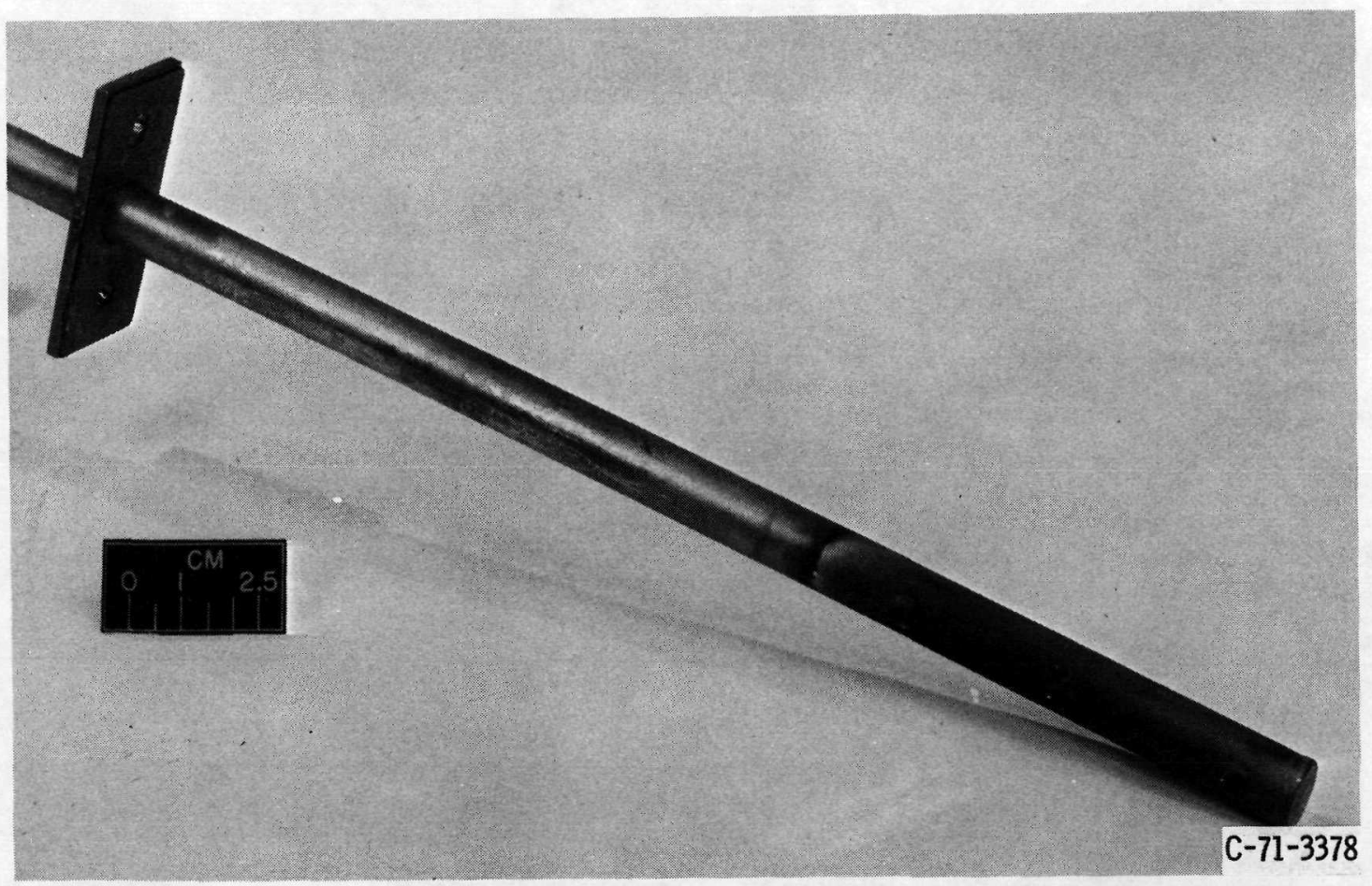

Figure 4. - Three-point gas sampling probe with water-cooled jacket. 


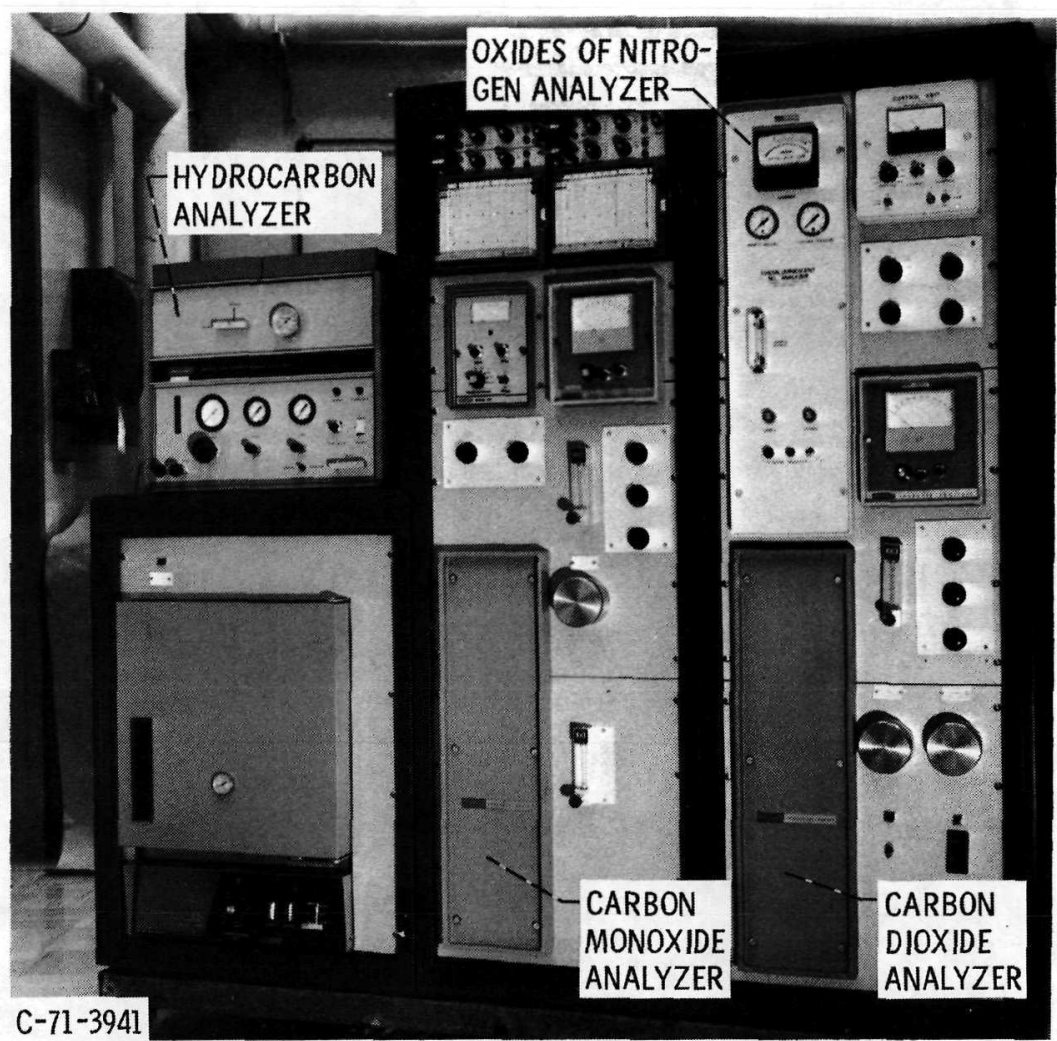

Figure 5. - Exhaust gas analysis system.

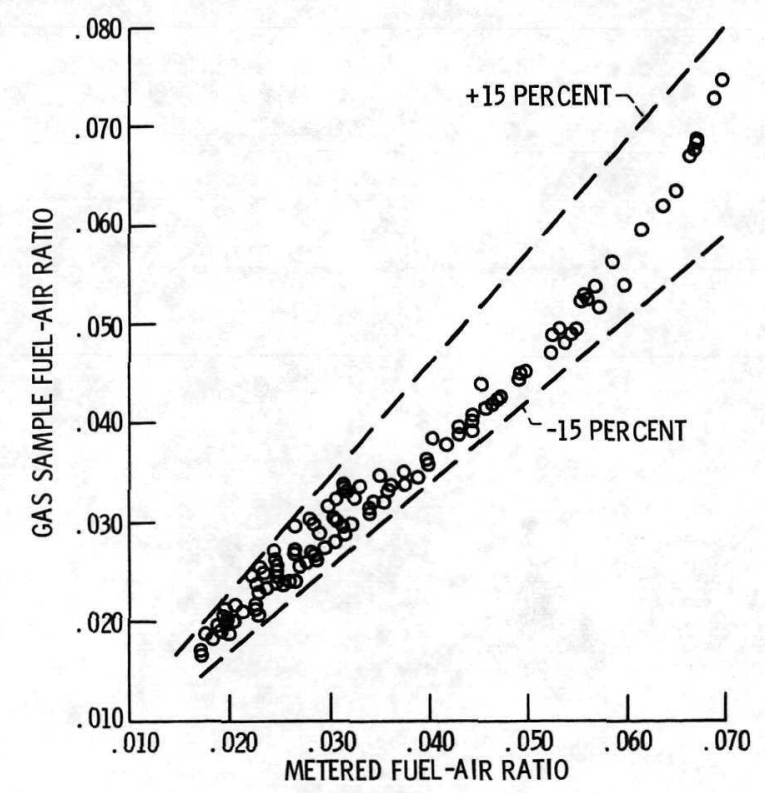

Figure 6. - Sample validity check. 


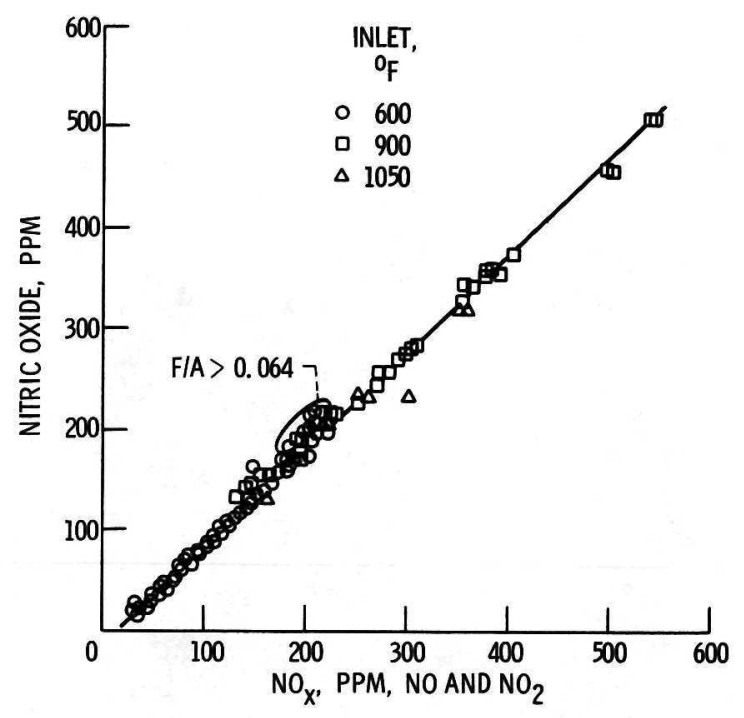

Figure 7. - $\mathrm{NO}$ and $\mathrm{NO}_{x}$ concentrations.

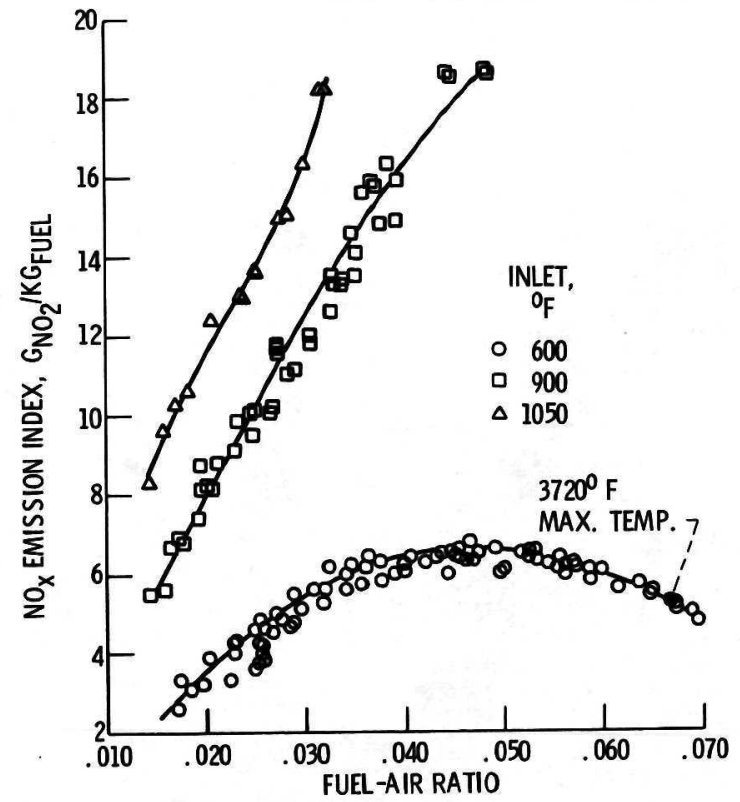

Figure 8. - Effects of combustor inlet temperature and fuel-air ratio on oxides of nitrogen formation. Combustor inlet pressure, 5 to 6 atmospheres: airflow, 85 to $110 \mathrm{lb} / \mathrm{sec}$.

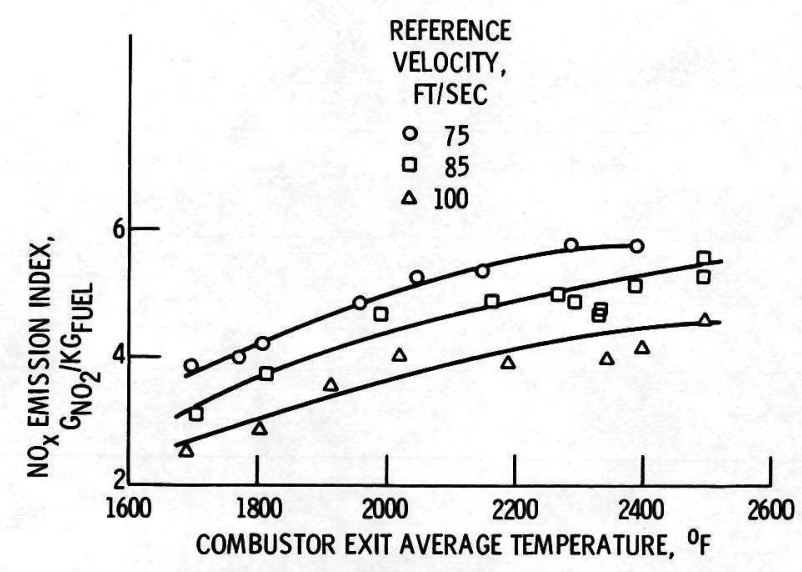

Figure 9. - Effects of combustor reference velocity on oxides of nitrogen formation. Combustor inlet air temperature, $600^{\circ} \mathrm{F}$. 

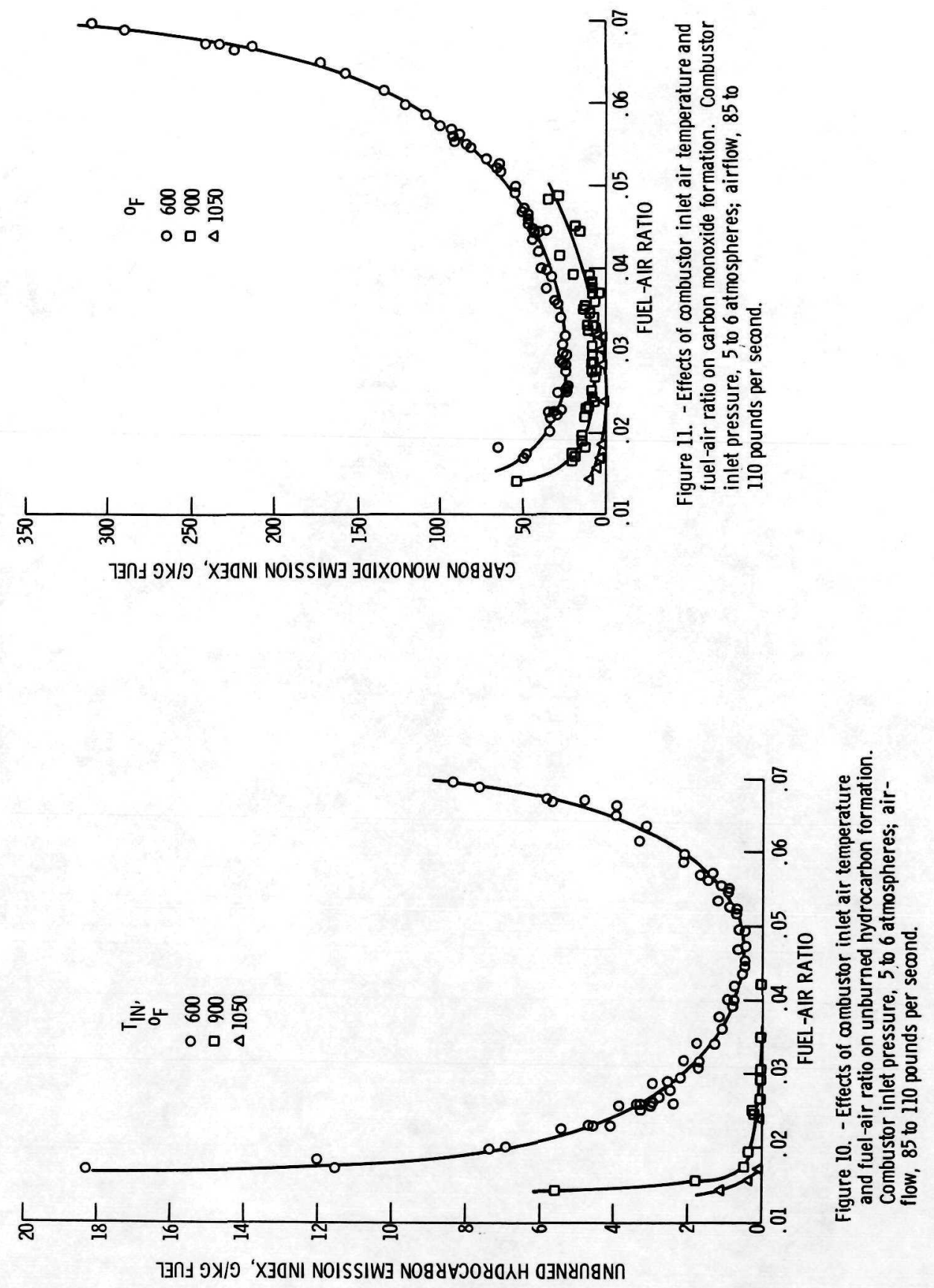


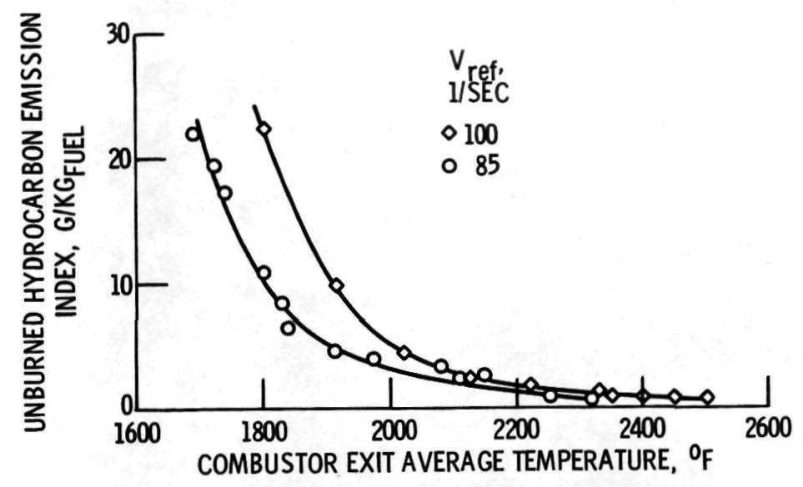

Figure 12. - Effects of combustor reference velocity on unburned hydrocarbon formation. Combustor inlet air temperature, $600^{\circ} \mathrm{F}$.

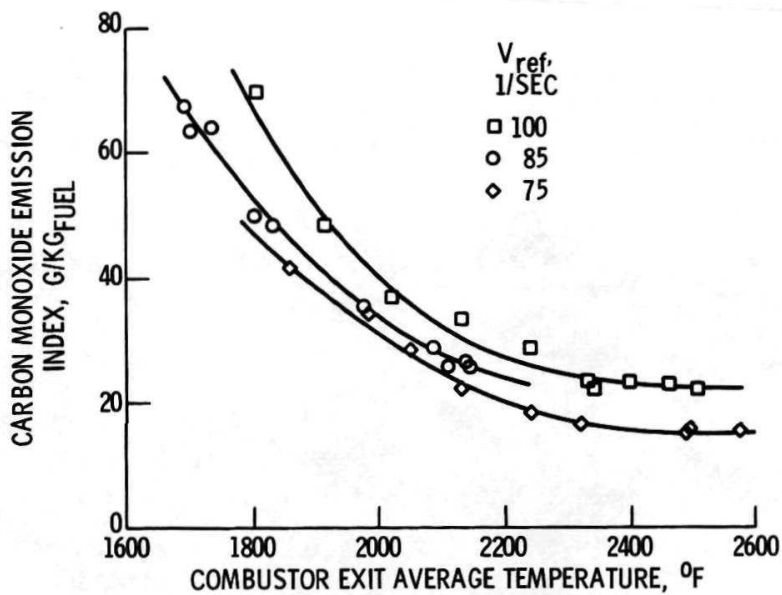

Figure 13. - Effects of combustor reference velocity on carbon monoxide formation. Combustor inlet air temperature, $600^{\circ} \mathrm{F}$.
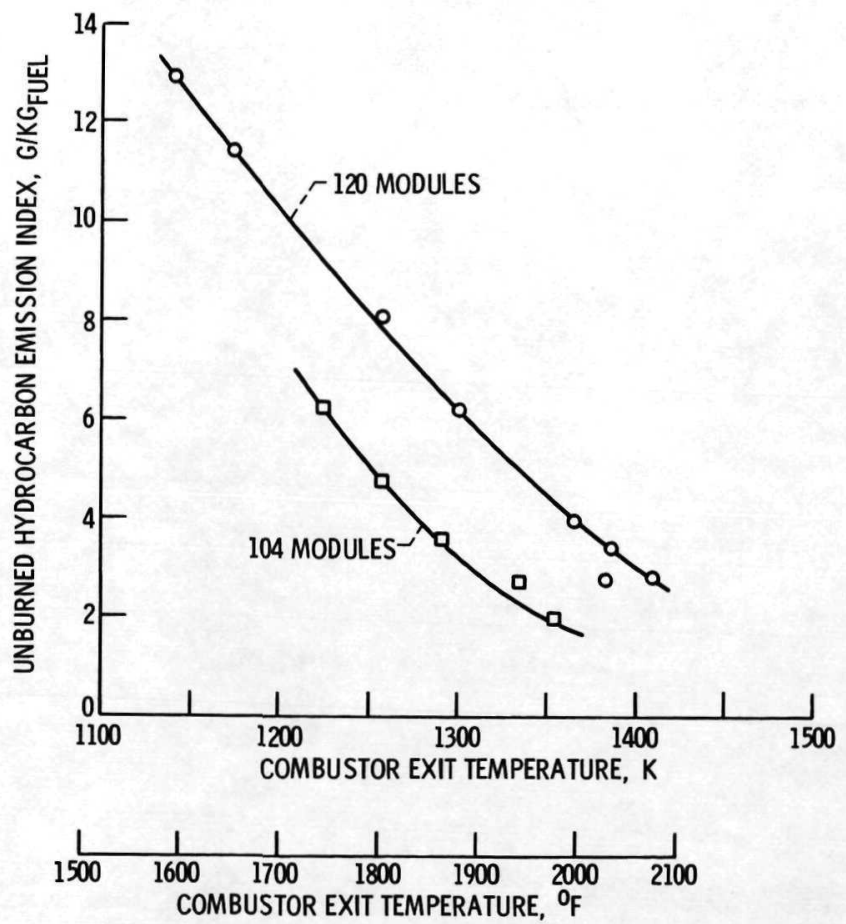

Figure 14. - Module number effect. Inlet air temperature, $589 \mathrm{~K}$ $\left(600^{\circ} \mathrm{F}\right)$; inlet air pressure, 6 atmospheres; reference velocity, 26 meters per second $(85 \mathrm{ft} / \mathrm{sec})$. 


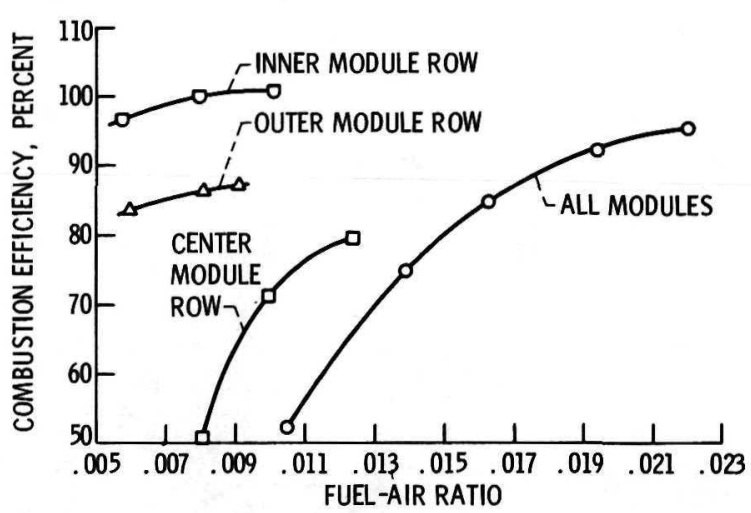

Figure 15. - Combustor efficiency during idle tests, Inlet air temperature, $478 \mathrm{~K}\left(400^{\circ} \mathrm{F}\right)$; inlet air pressure, 4 atmospheres; reference velocity, 26 meters per second $(85 \mathrm{ft} / \mathrm{sec})$.

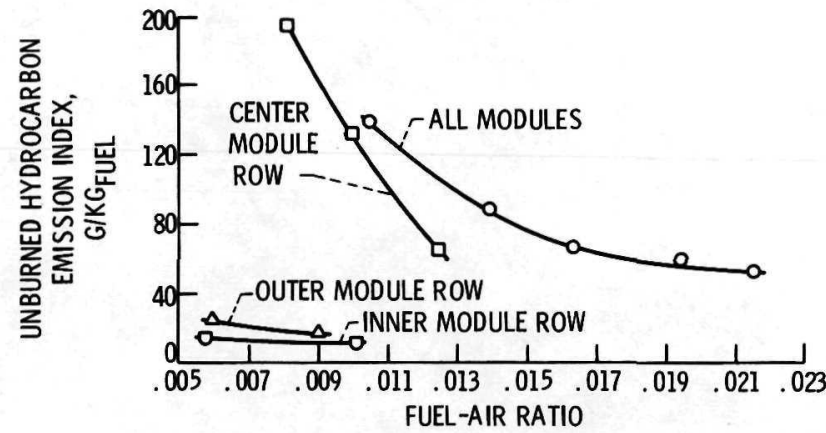

Figure 16. - Unburned hydrocarbon emissions during idle tests. Inlet air temperature, $478 \mathrm{~K}\left(400^{\circ} \mathrm{F}\right)$; inlet air pressure, 4 atmospheres; reference velocity, 26 meters per second $(85 \mathrm{ft} / \mathrm{sec})$.

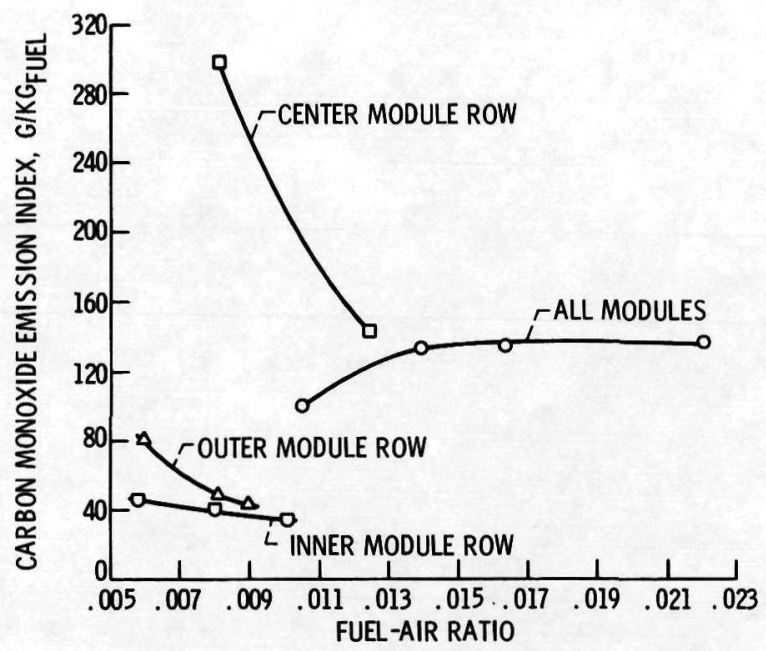

Figure 17. - Carbon monoxide emissions during idle tests. Inlet air temperature, $478 \mathrm{~K}\left(400^{\circ} \mathrm{F}\right)$; inlet air pressure, 4 atmospheres; reference velocity, 26 meters per second ( $85 \mathrm{ft} / \mathrm{sec})$. 